\title{
FORMULATION AND EVALUATION OF DIAZEPAM-LOADED INTRAVAGINAL ALGINATE BEADS: AN INVESTIGATION STUDY FOR THE TREATMENT OF PELVIC FLOOR DYSFUNCTION
}

\author{
SHEREEN AHMED SABRY* \\ Department of Pharmaceutics and Industrial Pharmacy, Faculty of Pharmacy, Zagazig University, Zagazig, Egypt. \\ Email: Shereensabry134@yahoo.com
}

Received: 09 February 2018, Revised and Accepted: 28 March 2018

\begin{abstract}
Objective: The fundamental objective of this research investigation was to develop intravaginal diazepam (DZ)-loaded alginate beads for the management of acute pelvic floor dysfunction (PFD) pain with minimal sedative effect.

Methods: DZ loaded beads were prepared by an ionotropic gelation method using SA (sodium alginate) alone, or in combination with either poloxamer 407 (PL), pectin (PC), or xanthan gum (XG) at different ratios in the presence of different concentrations of calcium chloride as a cross-linking agent. The successfully developed beads were evaluated for the particle size, pH, yield percentage, entrapment efficiency, in vitro bioadhesion, swelling percentage, and in vitro drug release. The stability, ex vivo drug permeation, and sedative action of the optimized beads formulations were studied.

Results: The particle size of the formulated beads was from $395 \pm 3.3$ to $515 \pm 2.8 \mu \mathrm{m}$, yield percentage was from $68.2 \pm 1.7$ to $87.5 \pm 2.1$, entrapment efficiency was from $65.6 \pm 1.6$ to $87.5 \pm 2.1$. $\mathrm{pH}$ ranged from $6.1 \pm 0.2$ to $6.8 \pm 0.6$, bioadhesion strength was from $71.5 \pm 1.3$ to $87.6 \pm 3.1$, and swelling percentage was in the range from $53.4 \pm 3.1$ to $85.2 \pm 3.7$. Approximately $92.4-72.6 \%$ of the loaded dose was released from the prepared beads. The optimized beads showed a good stability under the selected storage conditions. About 74.8\%, 71.1\%, 68.6\%, and 63.4\% of the loaded dose permeated through the rabbit vaginal mucosa from F7, F9, F3, and F11, respectively. The formulated beads decreased the sedative action associated with orally or parenterally administered DZ.
\end{abstract}

Conclusion: The developed beads were considered a promising candidate to formulate DZ into a new dosage form for the treatment of PFD with a minimum central nervous system sedation.

Keywords: Diazepam, Intravaginal alginate beads, Ionotropic gelation, Pelvic floor dysfunction.

(C) 2018 The Authors. Published by Innovare Academic Sciences Pvt Ltd. This is an open access article under the CC BY license (http://creativecommons. org/licenses/by/4. 0/) DOI: http://dx.doi.org/10.22159/ajpcr.2018.v11i7.25213

\section{INTRODUCTION}

The vaginal drug delivery system is currently of great interest in producing local and systemic action $[1,2]$. The importance of the vagina as a route of drug administration comes from its rich blood supply, large surface area, high permeability to several drugs, in addition to the avoidance of the first-pass metabolism [3]. Mucoadhesion has been of great interest in the development of vaginal drug delivery systems to increase the residence time at the site of absorption [4]. Sharma et al. formulated alginate beads loaded with voglibose for the effective treatment of hyperglycemia [5]. It was reported that glipizide-loaded alginate-chitosan microspheres were an effective approach for the treatment of diabetes [6]. Abdellatif et al. formulated flurbiprofen into calcium alginate beads to mask the drug taste and its burning effect in the oral cavity and stomach and to improve its poor bioavailability due to extensive first-pass metabolism [7]. Bioadhesive polymers such as $\mathrm{SA}, \mathrm{XG}, \mathrm{PC}$, and PL exhibited a good stability in a wide range of $\mathrm{pH}$ and were considered good candidates for the vaginal drug delivery [8]. Pelvic floor dysfunction (PFD) is a collective term for a variety of disorders that occur when pelvic floor muscles and ligaments are impaired. Sexual pain, pelvic pain, pressure, incontinence, incomplete emptying, and visible organ protrusion are the most important symptoms [9]. Up to $50 \%$ of women have been reported to develop PFD [10]. The widening of the pelvic floor hiatus and descending of the pelvic floor below the pubococcygeal line with specific organ prolapsing has been considered the main cause of PFD which usually associated with obesity, pregnancy, childbirth, or inherited deficiency of collagen which induces weakness of the connective tissue [9]. Benzodiazepines were considered the best treatment for the acute management of the severe pain associated with PFD, particularly diazepam (DZ). DZ is a long- acting benzodiazepine which recently was used for the management of PFD due to its sedative muscle relaxant and amnesic properties. Currently, vaginal DZ suppositories or tablets are prescribed to relieve the pain of interstitial cystitis, vulvar pain, sexual pain, and to decrease the sedation of parenteral or oral DZ [11]. Copra et al. developed vaginal pessaries loaded with DZ for the treatment of interstitial cystitis [12]. Balkis reported that the best release of DZ was achieved by the use of either glycerol gelatin or glycerol-PEG1540 suppository base [13]. The fundamental goal of this research investigation was the development of DZ-loaded vaginal beads as a novel treatment approach for PFD and the decrease of the sedation associated with oral or intravenous DZ.

\section{MATERIALS AND METHODS}

\section{Materials}

DZ, SA, PL, PC, and XG were kindly supplied by EIPICO Company, Egypt. Calcium chloride $\left(\mathrm{CaCl}_{2}\right)$, acetonitrile, methanol, and potassium dihydrogen orthophosphate were purchased from El-Nasr Company, Egypt. All other chemicals were of analytical grade.

\section{Methods}

Formulation of alginate beads

Ionotropic gelation method was used for the preparation of DZ-loaded beads $[14,15]$. Accurately weighed amount of SA was dissolved in phosphate buffer $\mathrm{pH} 6.5$ by stirring under gentle heating. PL or other mucoadhesive polymers was added to this solution. After $5 \mathrm{~min}$, DZ was added with constant stirring for homogeneous distribution. The formed dispersion was sonicated for $20 \mathrm{~min}$ to remove any air bubbles. Then, the solution was set aside for another $20 \mathrm{~min}$. The resulted 
solution was dropped through a 22 -gauge syringe with 0.8 -mm internal diameter from a distance of $5 \mathrm{~cm}$ into $100 \mathrm{ml} \mathrm{CaCl}_{2}$ solution at different concentrations as a cross-linking agent at 400 RPM and ambient room temperature. The drop-in rate was kept constant $(2 \mathrm{ml} / \mathrm{min})$. The formed beads were left for $30 \mathrm{~min}$ under stirring as a curing time. Finally, the beads were filtered, washed, and dried in a vacuum oven at $40^{\circ} \mathrm{C}$ for $24 \mathrm{~h}$. The composition of the successful DZ beads is given in Table 1.

\section{Characterization of DZ loaded beads}

Particle size analysis

The particle size of different beads formulations was determined by counting 100 beads using a calibrated optical microscope [16]

pH

$20 \mathrm{mg}$ of each formula was allowed to swell into $20 \mathrm{ml}$ distilled water for $5 \mathrm{~h}$. Then, the $\mathrm{pH}$ of the solution was determined using a $\mathrm{pH}$ meter (JENCO Model-5005 USP).

\section{Yield percentage}

The prepared alginate beads were filtered, collected, dried, and weighed. The total yield percentage was determined based on the dried weight of the drug and the polymers according to the following equation.

$$
\text { Yield percentage }=\frac{\text { Actual weight of the product }}{\text { Total weight of the drug and excipient }} \times 100
$$

\section{Entrapment efficiency}

Accurately weighed quantity of the formed beads equivalent to $10 \mathrm{mg}$ of the drug was crushed, suspended in $100 \mathrm{ml}$ phosphate buffer $\mathrm{pH} 6.5$ and stirred at $100 \mathrm{RPM}$ at $25^{\circ} \mathrm{C}$ in a thermostatic shaker water bath (Julabo SW-20 C, Germany) till equilibrium [15]. The solution was filtered, suitably diluted and the drug entrapped was determined by RP-C18 HPLC method using a mobile phase consisting of acetonitrile, methanol, and $1 \%$ phosphate buffer $(\mathrm{pH} 3)$ in a ratio of 18:58:24 (v/v/v) at a flow rate of $1 \mathrm{ml} / \mathrm{min}$ and the effluent was monitored using UV detection at $232 \mathrm{~nm}$ [17] against drug free beads as a blank.

$$
\text { Entrapment efficiency }=\frac{\text { Actual drug content }}{\text { Theoretical drug content }} \times 100
$$

\section{In vitro bioadhesion}

In vitro bioadhesion of the formulated beads was determined by a previously reported method [8]. The vagina of the overnight fasted female rabbits was removed, cut into square pieces measuring $2 \mathrm{~cm} \times 2 \mathrm{~cm}$, and rinsed with phosphate buffer $\mathrm{pH} 6.5 .50 \mathrm{mg}$ of the prepared alginate beads were placed onto the vaginal mucosa, at ambient room temperature for $30 \mathrm{~min}$. The vaginal mucosa was then rinsed with phosphate buffer $\mathrm{pH} 6.5$ and the washings were dried in a vacuum oven at $40^{\circ} \mathrm{C}$. The percentage of the bioadhesion was determined according to the following equation:

$$
\text { Bioadhsion percent }=\frac{\text { Theadhered beads }}{\text { Theapplied beads }} \times 100
$$

\section{Swelling percentage}

About $50 \mathrm{mg}$ of each formula was accurately weighed and placed in a wire basket of USP dissolution apparatus type II. The basket was then immersed in $500 \mathrm{ml}$ phosphate buffer $\mathrm{pH} 6.5$, at $37^{\circ} \mathrm{C}$ and 50 RPM. The beads were removed after $1 \mathrm{~h}$, dried with tissue paper, and weighed $[18,19]$. Swelling percentage was determined according to the following equation:

Swelling $(\%)=\frac{\left(\mathrm{W}_{\mathrm{t}}-\mathrm{W}_{0}\right)}{\mathrm{W}_{0}} \times 100$

Where $\mathrm{W}_{0}$ is the weight of the dried beads and $\mathrm{W}_{\mathrm{t}}$ is the weight of the swollen beads after $1 \mathrm{~h}$.

\section{In vitro disintegration of the capsules}

To facilitate the administration of the prepared beads, they were filled into hard gelatin capsules. Watch glass method was used for the determination of the in vitro disintegration of the capsules. One capsule was placed at the center of a watch glass $(11 \mathrm{~cm}$ in diameter $)$. The watch glass was placed in a thermostatic shaker water bath at $37^{\circ} \mathrm{C}$ and $50 \mathrm{RPM}$. About $4 \mathrm{ml}$ phosphate buffer $\mathrm{pH} 6.5$ was added to the capsule. The time at which the beads were released from the capsule was the disintegration time [8]

\section{In vitro drug release study}

In vitro drug release studies were carried out in $900 \mathrm{ml}$ phosphate buffer pH 6.5 at $37^{\circ} \mathrm{C}$ and 100 RPM using USP dissolution apparatus type II (basket type). Accurately weighed quantity of each formula equivalent to $10 \mathrm{mg}$ DZ was placed into the basket. $3 \mathrm{ml}$ samples were removed hourly for $8 \mathrm{~h}$ and replaced with an equal volume of a fresh buffer maintained at the same conditions. The withdrawn samples were filtered, suitably diluted and the drug content was determined by RP-C18 HPLC method at $232 \mathrm{~nm}$ [20].

\section{Ex vivo drug permeation study}

In this study, Franz diffusion cell was used. The model mucosal membrane was the rabbit vaginal mucosa. The vaginal mucosa was washed with phosphate buffer $\mathrm{pH} 6.5$ and mounted between the receptor and the donor compartments. The receptor compartment was filled with $25 \mathrm{ml}$ phosphate buffer $\mathrm{pH} 6.5$, kept at $37^{\circ} \mathrm{C}$, and stirred at $50 \mathrm{RPM}$ with $3 \mathrm{ml}$ samples were removed hourly for $8 \mathrm{~h}$ and replaced with fresh samples maintained at the same conditions. The permeated quantity of the drug was determined at 232 using RP-C18 HPLC method.

\section{Stability study}

The optimized DZ-loaded beads formulations were subjected to the stability study according to the ICH guidelines. The optimized formulae were placed at $40^{\circ} \mathrm{C}$ and $75 \pm 1 \mathrm{RH}$ for 3 months. The samples were removed monthly and evaluated for their physical appearance, entrapment efficiency, and cumulative release percentage after $8 \mathrm{~h}$ [21].

\section{Pharmacological study}

To estimate the sedative action of the prepared intravaginal DZ-loaded alginate beads, the optimized formulations F3, F7, F9, and F11 were subjected to some behavioral psychopharmacological tests.

\section{Study design}

White albino female mice (20-25 g) were used in this study. Animals were housed at the standardized condition of the animal house of Faculty of Pharmacy, Zagazig University, Zagazig, Egypt. All animals were acclimatized and kept constant at ambient room temperature. All animal procedures were performed in accordance with the approved protocol for the use of the experimental animals set by the standing committee of the animal care of the faculty of pharmacy, Zagazig

Table 1: Composition of different formulations of DZ-loaded alginate beads

\begin{tabular}{llllll}
\hline $\begin{array}{l}\text { Formula } \\
\text { code }\end{array}$ & DZ:SA & DZ:SA:PL & DZ:SA:PC & DZ:SA:XG & $\begin{array}{l}\mathbf{C a C l}_{2} \\
(\% \mathbf{W} / \mathbf{)}\end{array}$ \\
\hline F1 & $1: 1$ & - & - & - & 1 \\
F2 & $1: 3$ & - & - & - & 1 \\
F3 & $1: 5$ & - & - & - & 1 \\
F4 & $1: 1$ & - & - & - & 2 \\
F5 & $1: 1$ & - & - & - & 3 \\
F6 & - & $1: 1: 1$ & - & - & 1 \\
F7 & - & $1: 1: 2$ & - & - & 1 \\
F8 & - & - & $1: 1: 1$ & - & 1 \\
F9 & - & - & $1: 1: 2$ & - & 1 \\
F10 & - & - & - & $1: 1: 1$ & 1 \\
F11 & - & - & - & $1: 1: 2$ & 1 \\
\hline
\end{tabular}

DZ: Diazepam, SA: Sodium alginate, PL: Poloxamer 407, PC: Pectin, XG: Xanthan gum, $\mathrm{CaCl}_{2}$ : Calcium chloride (cross-linking agent) 
University, Egypt P12-12-2017. The animals were divided into seven groups, each of six mice. Group 1 act as a control and received distilled water $(10 \mathrm{ml} / \mathrm{kg}, \mathrm{PO})$, Group 2 act as positive control and received DZ ( $3 \mathrm{mg} / \mathrm{kg}$, IP), Group 3 act as positive control and received DZ (3 mg/kg, P0) [22], and Group 4, 5, 6, and 7 received the optimized formulations F3, F7, F9, and F11, respectively (3 mg/kg, intravaginal).

\section{Traction test}

Mice were suspended individually from their anterior limbs to a wire that was horizontally stretched. The mice that were considered under sedation were the mice that failed to reestablish, at least one of their posterior limbs reached the wire. The reaction was considered positive when the mice performed immediate reestablishment. Otherwise, the reaction was considered negative [23].

\section{Hole board test}

The mice were placed individually in the center of perforated wood board measuring $40 \mathrm{~cm} \times 40 \mathrm{~cm} \times 25 \mathrm{~cm}$, in which evenly spaced holes were made. The number of the head dips was counted during a period of $5 \mathrm{~min}$. The number of head dips was determined by the number of explored holes [24].

\section{Kinetic analysis}

In vitro release and ex vivo permeation data were subjected to theoretical analysis to estimate the kinetic order according to Higuchi diffusion, zero order, first order, Korsmeyer-Peppas, and Hixson and Crowell. [25].

\section{Statistical analysis}

All experiments were run in triplicates. The obtained results were expressed as mean \pm standard deviation. ANOVA was used to determine the significance. The results were considered statistically significant at $\mathrm{p}<0.05$.

\section{RESULTS AND DISCUSSION}

DZ-loaded alginate beads were prepared by an ionotropic gelation method using SA alone or in combination with other mucoadhesive polymers such as $\mathrm{PL}, \mathrm{PC}$, or XG.

\section{Particle size}

The mean particle size of the prepared beads is illustrated in Table 2 . The mean bead size was from $415 \pm 2.7 \mu \mathrm{m}$ to $502 \pm 2.7 \mu \mathrm{m}$. The polymer concentration had an obvious effect on the bead size. It was found that as DZ:SA ratio increased from 1:1 to 1:5, there was a significant increase in the mean bead size from $431 \pm 2.3 \mu \mathrm{m}$ (F1) to $502 \pm 2.7 \mu \mathrm{m}$ (F3). The increase in the bead size with the increase in the alginate concentration may be ascribed to the increase in the viscosity of the polymer dispersion [26]. These findings were in a good correlation with Kashid et al., who found that there was a significant increase in SA beads size from $0.06 \pm 0.02 \mathrm{~mm}$ to $0.11 \pm 0.014 \mathrm{~mm}$ with the increase in the $\mathrm{SA}$ amount from $100 \mathrm{mg}$ to $300 \mathrm{mg}$ at $6 \% \mathrm{CaCl}_{2}$ [27].

It is clear from the results in Table 2, that, the concentration of the cross-linking agent played a crucial role in the formulated beads size.
It was found that as the concentration of $\mathrm{CaCl}_{2}$ was increased from $1 \%$ to $2 \%$, there was a significant reduction in the mean beads size from $431 \pm 2.3 \mu \mathrm{m}$ (F1) to $415 \pm 2.7 \mu \mathrm{m}$ (F4). Further increase of $\mathrm{CaCl}_{2}$ concentration to $3 \%$, resulted in an additional reduction of the beads size to $395 \pm 3.3 \mu \mathrm{m}$ (F5). This was in a great accordance with Manjanna et al., who reported a significant reduction of the bead size from $734.1 \pm 0.54$ to $688.5 \pm 1.25 \mu \mathrm{m}$ with an increase in $\mathrm{CaCl}_{2}$ concentration from $2 \%$ to $5 \%$ [28]. This could be discussed on the basis that ionic gelation occurred immediately when a drop of alginate dispersion came into contact with calcium ions. As calcium ion penetrated the interior of the droplets, water was squeezed out of them resulted in the contraction of the formed beads. The high concentration of the crosslinking agent favors the shrinkage of the resulting beads and eventually a significant reduction in the mean bead size [29].

The addition of $\mathrm{PL}, \mathrm{PC}$, or $\mathrm{XG}$ to the alginate dispersion in a ratio of 1:1:1 (DZ:SA:additional polymer), resulted in a significant increase in the beads size to $455 \pm 2.8 \mu \mathrm{m}$ (F6), $458 \pm 3.1 \mu \mathrm{m}$ (F8), and $485 \pm 3.6 \mu \mathrm{m}$ (F10), respectively, compared to F1 $(431 \pm 2.3 \mu \mathrm{m})$. A further increase in the ratio to $1: 1: 2$, resulted in a corresponding increase in the beads size to $470 \pm 4.2 \mu \mathrm{m}$ (F7), $496 \pm 2.8 \mu \mathrm{m}$ (F9), and $515 \pm 2.8 \mu \mathrm{m}$ (F11), respectively. Sankula et al. reported an increase in the mean bead size with the addition of Cbp974 to SA dispersion [30]. Pal et al. found that the increase in the viscosity of the polymer dispersion resulted in the formation of big size droplets which contained more mass and consumed more time to fall from the syringe than the lower viscous polymer dispersion [31].

\section{Yield percentage}

Results in Table 2 show the production yield percentage of the different beads formulations. It was found that there was a significant increase in the yield from $68.2 \% \pm 1.7$ (F1) to $85.1 \% \pm 1.4$ (F3), with the increase in DZ: SA ratio from 1:1 to 1:5. Jelvehgari et al. found that with an increase in DFS:polymer ratio from 1:2.5 to 1:7.5, there was a significant increase in the yield from $85.27 \%$ to $90.8 \%$, respectively [32]

An increase in the concentration of $\mathrm{CaCl}_{2}$ from $1 \%$ to $2 \%$, resulted in a significant increase in the yield from $68.2 \% \pm 1.7$ (F1) to $78.2 \% \pm 1.8$ (F4). A further increase in the concentration of cross-linking agent to $3 \%$ had a nonsignificant effect on the yield.

The addition of PL, PC, or XG to the alginate dispersion in a ratio of 1:1:1, resulted in a significant increase in the yield to $77.2 \pm 2.1$ (F6), 75.6 \pm 1.5 (F8), and $80.4 \pm 1.8$ (F10), respectively, compared to F1 $(68.2 \% \pm 1.7)$. A further increase in the ratio to $1: 1: 2$, resulted in a clear and significant increase in the yield to $85.4 \pm 1.8$ (F7), $87.1 \pm 2.1$ (F9), and $87.5 \pm 2.1$ (F11), respectively. These results were in a good agreement with was found by Sankula et al. [30].

\section{Entrapment efficiency}

The entrapment efficiencies of the prepared beads are given in Table 2 . There was a significant increase in the entrapment efficiency from 65.6 \pm 1.6 (F1) to $78.9 \pm 3.1$ (F3) with an increase in DZ:SA ratio from

Table 2: Particle size, yield percentage, and entrapment efficiency of different DZ-loaded alginate beads

\begin{tabular}{llll}
\hline Formula code & Bead size $(\boldsymbol{\mu m}) \pm$ SD $^{*}$ & Yield percentage \pm SD $^{*}$ & ${\text { Entrapment efficiency }(\%) \pm S D^{*}}$ \\
\hline F1 & $431 \pm 2.3$ & $68.2 \pm 1.7$ & $65.6 \pm 1.6$ \\
F2 & $470 \pm 3.1$ & $75.6 \pm 2.1$ & $71.2 \pm 2.1$ \\
F3 & $502 \pm 2.7$ & $85.1 \pm 1.4$ & $78.9 \pm 3.1$ \\
F4 & $415 \pm 2.7$ & $78.2 \pm 1.8$ & $70.2 \pm 2.1$ \\
F5 & $395 \pm 3.3$ & $77.2 \pm 2.1$ & $78.2 \pm 1.8$ \\
F6 & $455 \pm 2.8$ & $77.2 \pm 2.1$ & $68.2 \pm 2.1$ \\
F7 & $470 \pm 4.2$ & $85.4 \pm 1.8$ & $70.1 \pm 1.6$ \\
F8 & $458 \pm 3.1$ & $75.6 \pm 1.5$ & $70.6 \pm 2.4$ \\
F9 & $496 \pm 2.8$ & $87.1 \pm 2.1$ & $75.4 \pm 1.8$ \\
F10 & $485 \pm 3.6$ & $80.4 \pm 1.8$ & $72.6 \pm 2.6$ \\
F11 & $515 \pm 2.8$ & $87.5 \pm 2.1$ & $78.4 \pm 1.3$ \\
\hline
\end{tabular}

*Each result is the mean of three determinations \pm standard deviation. DZ: Diazepam 
1:1 to 1:5. An increase in SA concentration was accompanied with a progressive increase in the beads size which entrapped more drugs. The increase in alginate concentration resulted in the formation of a dense matrix structure which reduced the loss of the drug during the curing time [28].

An increase in $\mathrm{CaCl}_{2}$ concentration from $1 \%$ to $2 \%$, resulted in a significant increase in the entrapment of the drug from $65.6 \pm 1.6$ (F1) to $70.2 \pm 2.1$ (F4). Further increase to $3 \%$, resulted in a further increase in the drug entrapment to $78.2 \pm 1.8$ (F5). As the concentration of the cross-linking agent increased, the cross-linking of the polymer, and the compactness of the formed insoluble dense polymer matrix increased. This resulted in the entrapment of more drug and the reduction of the drug diffusion during the curing time [28]

The addition of PL at a ratio of 1:1:1 had a nonsignificant effect on the entrapment efficiency, but further increase in the ratio to 1:1:2 resulted in a significant increase to $70.1 \pm 1.6$ (F7)

The addition of either $\mathrm{PC}$ or $\mathrm{XG}$ to the alginate dispersion at a ratio of 1:1:1, resulted in a significant increase in DZ entrapment to 70.6 \pm 2.4 (F8) and $72.6 \pm 2.6$ (F10), respectively, compared to F1 (65.6 \pm 1.6$)$. A further increase in the entrapment to $75.4 \pm 1.8$ (F9) and $78.4 \pm 1.3$ (F11) was observed with the increase of the ratio to $1: 1: 2$, respectively. The significant increase in DZ entrapment within the beads with the addition of the associated polymers could be attributed to the increase in the viscosity of the polymer dispersion, which resulted in a larger dense matrix beads that entrapped more drug and prevent its diffusion during the curing time $[26,28]$.

\section{pH}

The $\mathrm{pH}$ of all prepared beads formulations was in the range from $6.1 \pm 0.2$ to $6.8 \pm 0.6$ which ensured that the prepared beads were nonirritable and safe to be administered into the vagina (Table 3 ).

\section{Swelling index}

The results in Table 3 depict the swelling percentages of different beads formulations after $1 \mathrm{~h}$. An increase in DZ:SA ratio from 1:1 to $1: 5$, resulted in a significant increase in the swelling percentage from $53.4 \pm 3.1$ (F1) to $68.4 \pm 3.5$ (F3), respectively. This was in a good agreement with Iswariya et al. [33].

Swetha et al. found that when the concentration of Cbp934 increased, the swelling percentage of celecoxib-loaded beads significantly increased [34].

There was a significant reduction in the swelling percentage from $53.4 \pm 3.1$ (F1) to $31.2 \pm 1.7$ (F4), with an increase in the concentration of $\mathrm{CaCl}_{2}$ from $1 \%$ to $2 \%$, respectively. Further increase in $\mathrm{CaCl}_{2}$ concentration to $3 \%$, resulted in an additional reduction to $23.2 \pm 2.1$ (F5). Jahan et al. reported a significant reduction in the swelling percentage of theophylline-loaded SA beads from $12.3 \%$ to $5.9 \%$, with

Table 3: Swelling percentage, bioadhesion strength, and $\mathrm{pH}$ of different DZ-loaded alginate beads

\begin{tabular}{llll}
\hline $\begin{array}{l}\text { Formula } \\
\text { code }\end{array}$ & $\begin{array}{l}\text { Swelling percentage } \\
\text { after } \mathbf{1} \mathbf{h} \pm \mathbf{S D}^{*}\end{array}$ & $\begin{array}{l}\text { Bioadhesion } \\
\text { strength } \mathbf{( \% )} \pm \text { SD }^{*}\end{array}$ & $\mathbf{p H} \pm \mathbf{S D}^{*}$ \\
\hline F1 & $53.4 \pm 3.1$ & $71.5 \pm 1.3$ & $6.3 \pm 0.8$ \\
F2 & $61.2 \pm 2.7$ & $76.8 \pm 1.8$ & $6.5 \pm 0.2$ \\
F3 & $68.4 \pm 3.5$ & $82.1 \pm 1.8$ & $6.5 \pm 0.1$ \\
F4 & $31.2 \pm 1.7$ & $66.2 \pm 1.5$ & $6.7 \pm 0.4$ \\
F5 & $23.2 \pm 2.1$ & $61.5 \pm 2.4$ & $6.1 \pm 0.2$ \\
F6 & $60.2 \pm 1.8$ & $74.2 \pm 1.8$ & $6.2 \pm 0.5$ \\
F7 & $66.3 \pm 1.5$ & $78.1 \pm 1.5$ & $6.2 \pm 0.7$ \\
F8 & $73.1 \pm 2.5$ & $80.2 \pm 2.1$ & $6.4 \pm 0.8$ \\
F9 & $85.2 \pm 3.7$ & $87.6 \pm 3.1$ & $6.6 \pm 0.8$ \\
F10 & $72.8 \pm 3.1$ & $79.5 \pm 2.1$ & $6.5 \pm 0.4$ \\
F11 & $83.2 \pm 2.8$ & $86.3 \pm 2.1$ & $6.8 \pm 0.6$ \\
\hline
\end{tabular}

*Each result is the mean of three determinations \pm standard deviation. DZ: Diazepam an increase in $\mathrm{CaCl}_{2}$ concentration from $5 \%$ to $10 \%$, respectively, [35]. An increase in the concentration of the cross-linking agent increased the extent of the polymer cross-linking which decreased the polymer chain length. The decrease in the polymer chain length decreased the ability of the polymer to expand and swell [36].

The addition of PL, PC, or XG to the alginate dispersion in a ratio of 1:1:1, resulted in a significant increase in the swelling percentage to $60.2 \pm 1.8$ (F6), $73.1 \pm 2.5$ (F8), and $72.8 \pm 3.1$ (F10), respectively, compared to F1 $(53.4 \pm 3.1)$. Further increase in the swelling percentage to $66.3 \pm 1.5$ (F7), 85.2 \pm 3.7 (F9), and 83.2 \pm 2.8 (F11), respectively, was observed with an increase in the ratio to $1: 1: 2$. This could be ascribed to the increase in the hydrophilicity of the polymer matrix [37].

\section{Bioadhesion strength}

Table 3 shows the bioadhesion strength of the different beads formulations. The results demonstrated an increase in the percentage of beads that adhered to the rabbit vaginal mucosa from $71.5 \pm 1.3$ (F1) to $82.1 \pm 1.8$ (F3) with an increase in DZ:SA ratio from 1:1 to $1: 5$, respectively. There was a significant increase in the maraviroc alginate microspheres mucoadhesion percentage after $4 \mathrm{~h}$ from $55 \pm 3.51$ to $78 \pm 2.08$ with an increase in the drug to polymer ratio from $1: 1$ to $1: 2$, respectively [21]. An increase in the concentration of SA resulted in an increase in the amount of free carboxylic group which was responsible for the binding to the sialic acid group of the vaginal mucosa [27].

An increase in the cross-linking agent concentration from $1 \%$ to $2 \%$, resulted in a significant decrease in the bioadhesion strength from 71 . $5 \pm 1.3$ (F1) to $66.2 \pm 1.5$ (F4). A further decrease in the bioadhesion strength to $61.5 \pm 2.4$ (F5) was obtained with a further increase in the cross-linking agent concentration to $3 \%$. The reduction of the bioadhesion strength could be discussed on the basis of the surface charge density. An increase in the extent of cross-linking resulted in a significant decrease in the surface-negative charge on the prepared alginate beads and consequently decreased the bioadhesion strength [38]. On incorporation of PL, PC, or $\mathrm{XG}$ within the alginate beads in a ratio of $1: 1: 1$, the bioadhesion strength of the resultant beads increased to $74.2 \pm 1.8$ (F6), 80.2 \pm 2.1 (F8), and $79.5 \pm 2.1$ (F10), respectively, compared to F1 (71.5 \pm 1.3$)$. A further increase in the polymer ratio to $1: 1: 2$, resulted in a further increase to $78.1 \pm 1.5$ (F7), 87.6 \pm 3.1 (F9), and $86.3 \pm 2.1$ (F11), respectively. This could be attributed to the increase of either hydroxyl group content or carboxylic group content or both of the prepared beads which resulted in more hydrogen bonding with the substrate [33].

\section{In vitro disintegration of the capsules}

It was found that the prepared beads formulations were completely released from the capsules after approximately $10 \mathrm{~min}$.

\section{In vitro release study}

The cumulative release profiles of the DZ from the prepared beads were depicted in Figs. 1-5. It was clear from Fig. 1 that the concentration of SA had a significant influence on the DZ release percentage after $8 \mathrm{~h}$. The cumulative percentage of DZ significantly decreased from $92.4 \%$ (F1) to $75.6 \%$ (F3), with an increase in DZ:SA ratio from 1:1 to 1:5, respectively (Fig. 1). This was in a good correlation with Rasel and Hasan, who found that the release of diclofenac sodium significantly decreased from $76.7 \%$ to $69.1 \%$, as the amount of SA increased from $2 \mathrm{~g}$ to $4 \mathrm{~g}$ [15]. This could be ascribed to the formation of a tight junction between the glucuronic acid residues as a result of cross-linking. An increase in SA concentration led to an increase in the number of cross-linking points, so more drug would be entrapped and eventually a significant reduction in the total drug release from the resulting beads [39]. This could also be attributed to the formation of gelatinous mass on the surface of the formed beads on contact with the dissolution medium which hindered further penetration of the dissolution medium and increased the diffusional pass length $[3,40]$.

As the concentration of $\mathrm{CaCl}_{2}$ increased from $1 \%$ to $2 \%$, there was a significant reduction in the DZ cumulative release percentage from 
92.4\% (F1) to $85.1 \%(\mathrm{~F} 4)$; further increase in the concentration of cross-linking agent to $3 \%$ induced further reduction in the percentage released to $76.5 \%$ (F5) (Fig. 2). An increase in the cross-linking agent concentration, led to the formation of more rigid gel structure with smaller pore size, which retained the drug and retarded the penetration of the dissolution medium into the beads which in turn decreased the total amount of the drug released [15]. This was in a good correlation with Mandal et al. who reported a significant decrease in the amount of trimetazidine dihydrochloride release from $38 \%$ to $30 \%$ with an increase in Cacl 2 concentration from $1 \%$ to $3 \%$ [41].

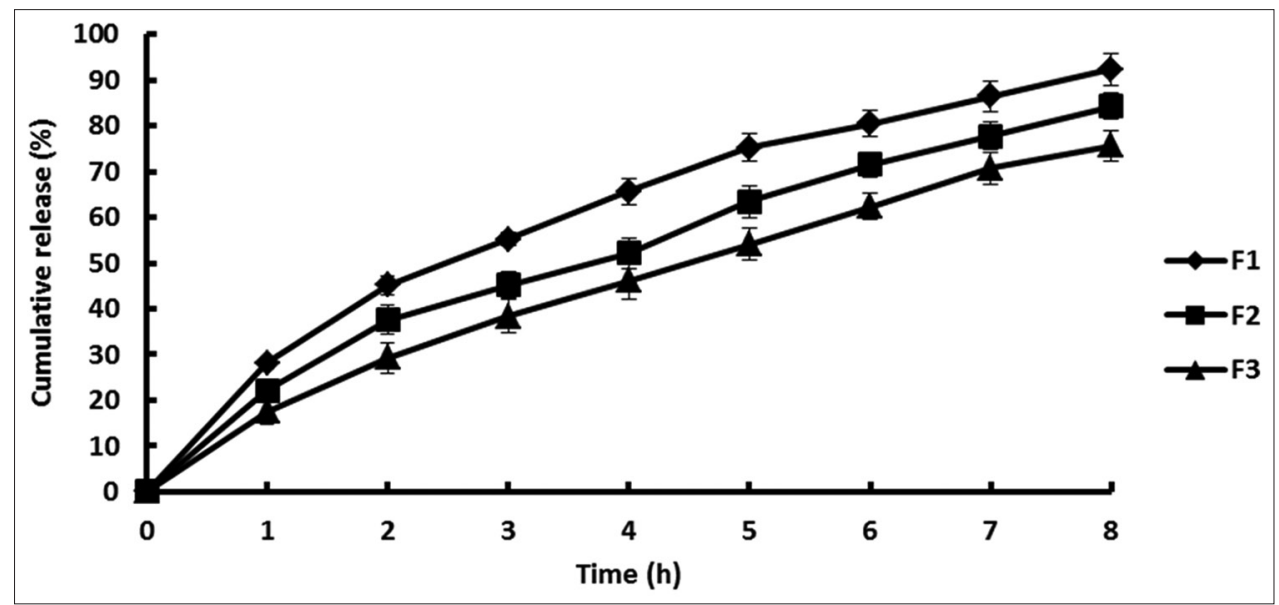

Fig. 1: Effect of sodium alginate:diazepam ratio on diazepam cumulative release percentage from alginate beads $n=3 \pm S D(s t a n d a r d$ deviation of the mean)

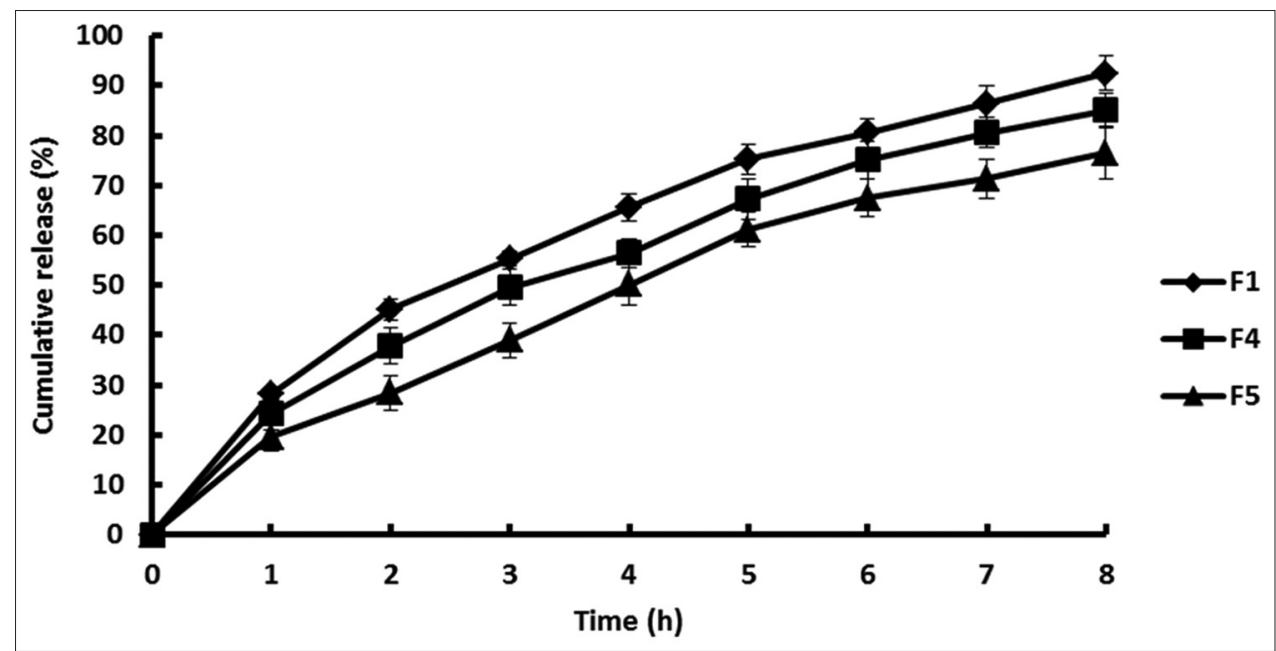

Fig. 2: Effect of cross-linking agent concentration $(\mathrm{CaCl} 2)$ on diazepam cumulative release percentage from alginate beads $\mathrm{n}=3 \pm \mathbf{s t a n d a r d}$ deviation

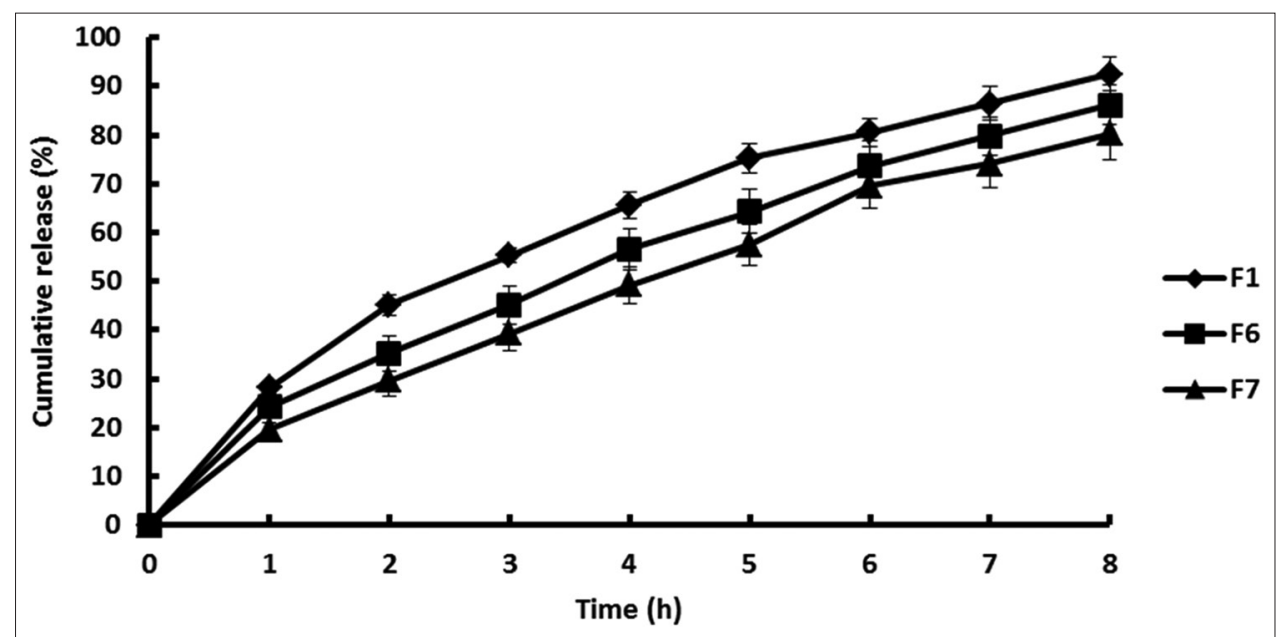

Fig. 3: Effect of sodium alginate:diazepam:poloxamer 407 ratio on diazepam cumulative release percentage from alginate beads $\mathrm{n}=3 \pm$ standard deviation 
The incorporation of PL at 1:1:1, significantly decreased the DZ release to $86.1 \%$ (F6) compared to $\mathrm{F} 1(92.4 \%)$. A further increase in the ratio to $1: 1: 2$, resulted in a further reduction in the release to $80.2 \%$ (F7)
(Fig. 3). Parhi and Suresh found that an increase in PL concentration from $0 \%$ to $1 \%$, resulted in a significant decrease in metoprolol succinate from $93.13 \%$ to $76.5 \%$, respectively [20].

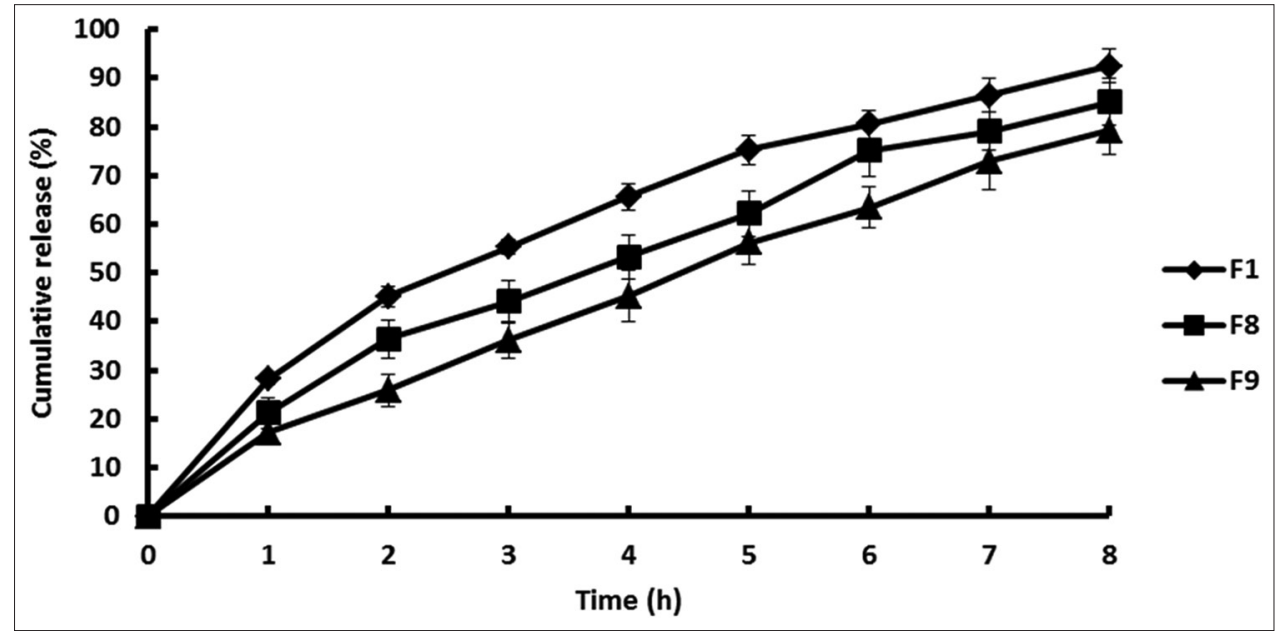

Fig. 4: Effect of sodium alginate: diazepam:pectin ratio on diazepam cumulative release percentage from alginate beads $n=3 \pm$ standard deviation.

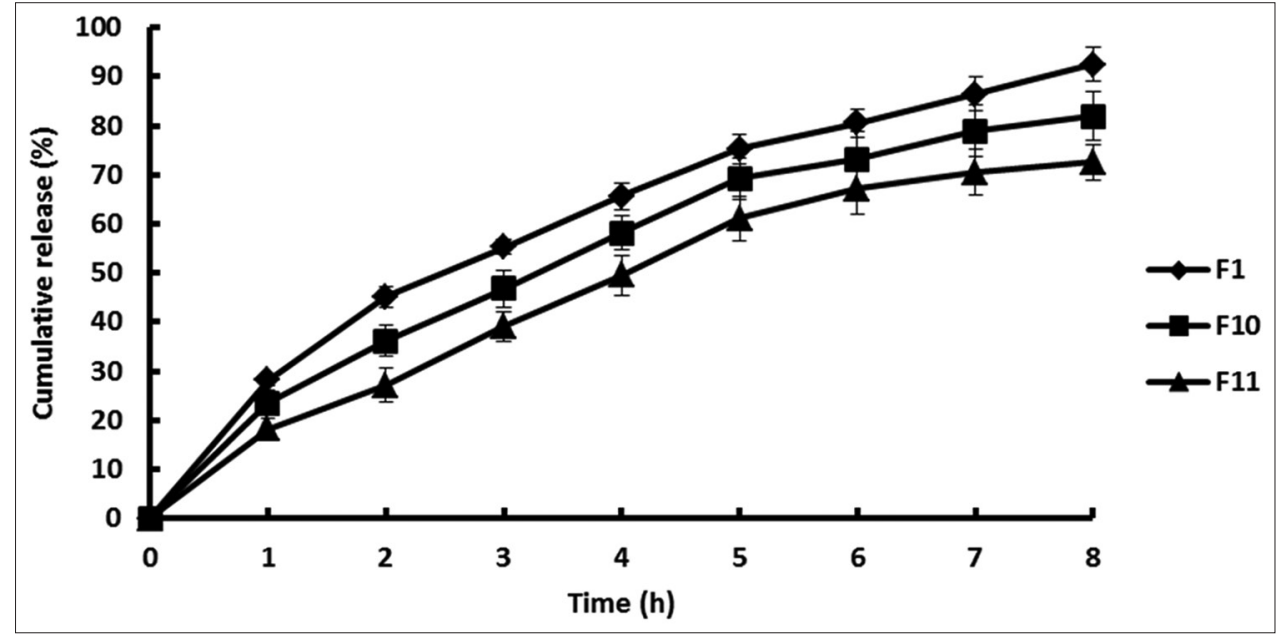

Fig. 5: Effect of sodium alginate:diazepam:xanthan gum ratio on diazepam cumulative release percentage from alginate beads $\mathrm{n}=3 \pm$ standard deviation

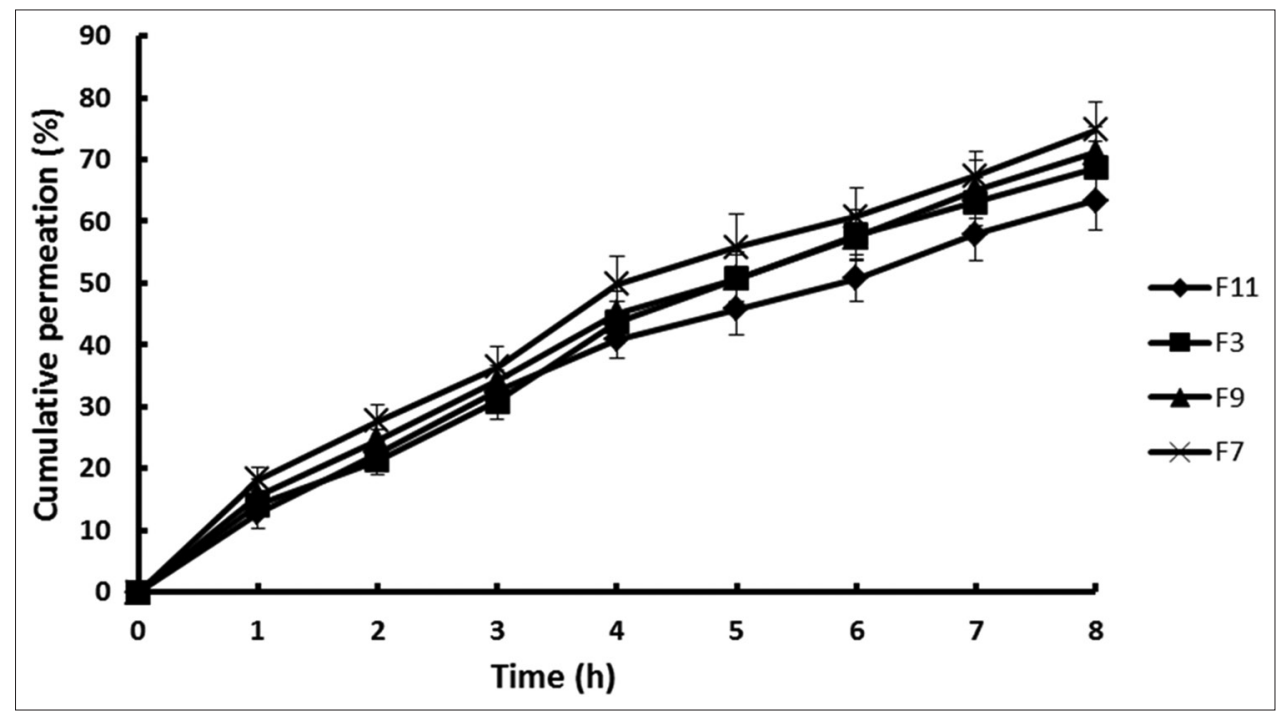

Fig. 6: Cumulative percentage of diazepam permeated through the rabbit vaginal mucosa $n=3 \pm s t a n d a r d ~ d e v i a t i o n$ 
addition of $\mathrm{PC}$ in a ratio of 1:1:1 significantly reduced the cumulative percentage after $8 \mathrm{~h}$ from $92.4 \%$ (F1) to $85.1 \%$ (F8). Further reduction in the release to $79.2 \%$ (F9) was obtained with further increase in the PC ratio to 1:1:2 (Fig. 4). Khan et al. found that verapamil HCL release from PC -alginate beads was lesser than its release from alginate beads only [14].

XG significantly decreased the DZ release percentage from 92.4\% (F1) to $81.9 \%(\mathrm{~F} 10)$ at $1: 1: 1$. Further increase in the ratio to $1: 1: 2$, resulted in a further reduction in the drug release to $72.6 \%$ (F11) (Fig. 5). Kulkarni et al. [42] reported a sustained release of glipizide from XGchitosan microbeads.

These results could be ascribed to the formation of less porous gel mass by either PL, PC, or XG along with the longer diffusion path length formed by the higher concentration of the incorporated polymers.

\section{Ex vivo drug permeation study}

Fig. 6 demonstrates the permeation profile of DZ through the rabbit vaginal mucosa. F3, F7, F9, and F11 were selected for the study based on their in vitro release profiles, entrapment efficiencies along with their bioadhesion strengths. It was found that about $74.8 \%, 71.1 \%, 68.6 \%$, and $63.4 \%$ of the loaded dose permeated through the rabbit vaginal mucosa from F7, F9, F3, and F11, respectively. Based on the release and permeation data, it was found that there was a good correlation between the in vitro release and ex vivo permeation of DZ which emphasized the effective therapeutic action of the prepared beads.

\section{Kinetic analysis}

The in vitro drug release and ex vivo drug permeation of the tested formulations followed Higuchi diffusion model.

\section{Stability study}

Based on the release profile, entrapment efficiency, and bioadhesion strength; F3, F7, F9, and F11 were selected for conducting the stability study by storing the selected formulations at $40^{\circ} \mathrm{C}$ and $75 \pm 1 \mathrm{RH}$ for 3 months. There was a negligible change in the tested parameters which ensured the good stability of the prepared beads (Table 4).

\section{Traction test}

Table 5 illustrates the reestablishment times performed by the studied animal groups. It was obvious that Group 1 reestablished immediately after 2 s. Group 2 and 3 responded after 30 and 22 s, respectively. Group 4, 5, 6, and 7 performed reestablishment after 11, 10, 13, and $11 \mathrm{~s}$, respectively. The significant reduction in the reestablishment time in the groups that received intravaginal alginate beads compared to the animal groups which received either IP or PO DZ indicated that the prepared alginate beads reduced the sedative action of the parenteral or oral DZ.

\section{Hole board test}

The results in Table 5 show the number of the explored holes of the studied groups. The significant increase in the number of head dips to $11,10,9$, and 12 for F3, F7, F9, and F11 respectively, compared to either IP DZ (1) or PO DZ (4), suggested also that, the formulation of DZ into intravaginal alginate beads successfully decreased its sedative action.

\section{CONCLUSION}

DZ has been successfully formulated into intravaginal beads using a variety of bioadhesive polymers which were easily administered into the vagina with minimum central nervous system side effects. The obtained results are promising to develop a clinical study to establish its therapeutic efficacy and safety on the PFD patients.

\section{AUTHOR CONTRIBUTION}

All the work has been conducted by the corresponding author

Table 4: Stability study of the optimized beads at $40^{\circ} \mathrm{C}$ and $75 \pm 1 \mathrm{RH}$

\begin{tabular}{|c|c|c|c|c|}
\hline Formula code & Time (months) & Entrapment efficiency $(\%) \pm S D^{*}$ & Bioadhesion strength $(\%) \pm S^{*}$ & Cumulative release $(\%) \pm S D^{*}$ \\
\hline \multirow[t]{4}{*}{ F3 } & 0 & $78.9 \pm 3.1$ & $82.1 \pm 1.8$ & $75.6 \pm 3.4$ \\
\hline & 1 & $77.2 \pm 2.7$ & $80.2 \pm \pm 1.5$ & $77.2 \pm 2.7$ \\
\hline & 2 & $79.8 \pm 1.8$ & $83.4 \pm 2.1$ & $76.8 \pm 4.1$ \\
\hline & 3 & $76.9 \pm 3.2$ & $82.9 \pm 2.7$ & $74.1 \pm 3.1$ \\
\hline \multirow[t]{3}{*}{ F7 } & 0 & $70.1 \pm 1.6$ & $78.1 \pm 1.5$ & $80.2 \pm 2.3$ \\
\hline & 1 & $69.1 \pm 2.7$ & $77.5 \pm 3.3$ & $80.9 \pm 3.1$ \\
\hline & 2 & $71.2 \pm 1.9$ & $79.5 \pm 2.1$ & $81.2 \pm 3.6$ \\
\hline \multirow[t]{4}{*}{ F9 } & 0 & $75.4 \pm 1.8$ & $87.6 \pm 3.1$ & $79.2 \pm 4.2$ \\
\hline & 1 & $75.6 \pm 2.1$ & $88.2 \pm 2.7$ & $77.8 \pm 3.6$ \\
\hline & 2 & $74.8 \pm 1.3$ & $85.9 \pm 1.9$ & $80.3 \pm 2.9$ \\
\hline & 3 & $75.1 \pm 2.1$ & $88.7 \pm 1.5$ & $79.9 \pm 3.6$ \\
\hline \multirow[t]{4}{*}{ F11 } & 0 & $78.4 \pm 1.3$ & $86.3 \pm 2.1$ & $72.6 \pm 2.7$ \\
\hline & 1 & $78.6 \pm 3.2$ & $87.5 \pm 1.9$ & $72.1 \pm 4.2$ \\
\hline & 2 & $77.5 \pm 2.7$ & $86.9 \pm 2.7$ & $73.1 \pm 5.3$ \\
\hline & 3 & $77.8 \pm 2.1$ & $88.1 \pm 2.7$ & $71.6 \pm 3.6$ \\
\hline
\end{tabular}

*Each result is the mean of three determinations \pm standard deviation.

Table 5: Sedative action of the optimized diazepam-loaded alginate beads

\begin{tabular}{llll}
\hline Animal group & Formula received & Traction test (reestablishment time (S) \pm SD* & Hole board test (explored holes during $\mathbf{5}$ min) \pm SD* \\
\hline 1 & Distilled water & $2 \pm 0.02$ & $18 \pm 1.2$ \\
2 & Diazepam (IP) & $30 \pm 0.4$ & $1 \pm 0.8$ \\
3 & Diazepam (PO) & $22 \pm 0.6$ & $4 \pm 0.1$ \\
4 & F3 & $11 \pm 0.09$ & $11 \pm 0.2$ \\
5 & F7 & $10 \pm 0.3$ & $10 \pm 0.8$ \\
6 & F9 & $13 \pm 0.5$ & $9 \pm 1.1$ \\
7 & F11 & $11 \pm 0.6$ & $12 \pm 0.9$ \\
\hline
\end{tabular}

*Each result is the mean of six determinations \pm standard deviation 


\section{ACKNOWLEDGMENT}

The author is thankful to EIPICO Company, Egypt, for providing the drug and polymers which were used in this work.

\section{CONFLICT OF INTEREST}

The author declares no conflict of interest.

\section{REFERENCES}

1. Acartürk F. Mucoadhesive vaginal drug delivery systems. Recent Patents Drug Deliv Form 2009;3:193-5.

2. Friend DR. Advances in vaginal drug delivery. Drug Deliv Transl Res 2011;1:183-4.

3. Kalita B, Saikia K, Kalita B. Formulation and evaluation of metronidazole microspheres-loaded bioadhesive vaginal gel. Asian J Pharm Clin Res 2017;10:418-24.

4. Kurana S, Madav NV. Review article on mucoadhesive drug delivery; Mechanism and method of evaluation. Int J Pharm Bio Sci 2011;2:458-67.

5. Sharma M, Jain K, Dev SK, Choudhury PK. Formulation and evaluation of sodium alginate beads by emulsion gelation method. Asian J Pharm 2017;11:101-6.

6. Sharma M, Choudhury PK, Dev SK. Formulation and in-vitro-in-vivo evaluation of alginate-chitosan microspheres of glipizide by ionic gelation method. Asian J Pharm Clin Res 2017;10:385-90.

7. Abdellatif AA, El Hamd MA, Saleh K. A formulation, optimization and evaluation of controlled released alginate beads loaded-flurbiprofen. J Nanomed Nanotechnol 2016;7:1-8.

8. Abass HA, Kamel R. Formulation and evaluation of in situ forming polymeric drug delivery systems for mixed vaginal infection. $\mathrm{Br} \mathrm{J}$ Pharm Res 2014;4:2281-95.

9. Boyadzhyan L, Raman SS, Raz S. Role of static and dynamic MR imaging in surgical pelvic floor dysfunction. Radiographics 2008;28:949-67.

10. Hagen S, Stark D. Conservative prevention and management of pelvic organ prolapse in women. Cochrane Database Syst Rev 2011;12:CD003882.

11. Rogalski MJ, Kellogg-Spadt S, Hoffmann AR, Fariello JY, Whitmore KE. Retrospective chart review of vaginal diazepam suppository use in high-tone pelvic floor dysfunction. Int Urogynecol J Pelvic Floor Dysfunction 2010;21:895-9.

12. Capra P, Perugini P, Bleve M, Pavanetto P, Musitelli G, Rovereto B, et al. Innovative approach for interstitial cystitis: Vaginal pessaries loaded diazepam - a preliminary study. J Pharm 2013;2013:1-7.

13. Balkis AK. The release of diazepam from different conventional and hollow type suppository bases. Iraqi J Pharm Sien 2007;16:21-5.

14. Khan AD, Bajpai M. Formulation and evaluation of floating beads of verapamil hydrochloride. Int J PharmTech Res 2011;3:1537-46.

15. Rasel MA, Hasan M. Formulation and evaluation of floating alginate beads of diclofenac sodium. Dhaka Univ J Pharm Sci 2012;11:29-35.

16. Ranvirsingh TA, Basavaraj BV, Bharath S, Deveswaran R, Madhavan V. Formulation and evaluation of floating alginate beads of an anti ulcer drug. Int J Pharm Sci Rev Res 2013;21:120-4.

17. Sruthi A, Tejaswi P, Thanuja N, Kumar DS, Sagar PV. Simple RP-HPLC method for estimation of diazepam in tablet dosage form. J Pharm Res 2013;6:140-4

18. Jaiswal D, Bhattacharya A, Yadav IK. Formulation and evaluation of oil entrapped floating beads of ranitidine hydrochloride. Int J Pharm Pharm Sci $2009 ; 1: 128-40$

19. Tiwari RK, Singh L, Sharma V. Performance optimization of sustained release arginine alginate microbeads with a natural polysaccharide. J Pharm Res Int 2017;17:1-11.

20. Parhi R, Suresh P. Alginate-poloxamer beads for controlled release of metoprolol succinate. Turk J Pharm Sci 2012;12:59-66.

21. Velmurugan S, Ali MA. Formulation and evaluation of maraviroc mucoadhesive microsheres by ionotropic gelation method. Int J Pharm Pharm Sci 2013;5:294-2

22. Aziz A, Khan IA. Pharmacological evaluation of sedative and hypnotic activities of methanolic extract of Lycopus europaeus in mice. J Phytopharmacol 2013;2:8-12

23. Courvoisier S, Ducrot R, Julou L, Garattini S, Ghetti V, editors. Psychotropic Drugs. Amsterdam: The Netherlands; 1957.

24. Clark G, Koester AG, Pearson DW. Exploratory behavior in chronic disulfoton poisoning in mice. Psychopharmacologia 1971;20:169-71.

25. Patel YL, Sher P, Pawar AP. The effect of drug concentration and curing time on processing and properties of calcium alginate beads containing metronidazole by response surface methodology. AAPS PharmSciTech 2006;7:86.

26. Das S, Samanta A, Bose A. Design, development and evaluation of fluconazole topical gel. Asian J Pharm Clin Res 2015;8:132-5.

27. Kashid P, Doijad R, Shete A, Sajan S, Bhagat A. Studies on rebamipide loaded gastroretentive alginate based mucoadhesive beads: Formulation and in-vitro, in-vivo evaluation. Pharm Methods 2016;7:132-8.

28. Manjanna KM, Shivakumar B, Pramod KT. Formulation of oral sustained release aceclofenac sodium microbeads. Int J Pharm Tech Res 2009;1:940-52.

29. Akifuddin SK, Abbas Z, Marihal S, Ranadev AK, Kumar SI, Kulkarni R. Preparation, characterization and in-vitro evaluation of microcapsules for controlled release of diltiazem hydrochloride by ionotropic gelation technique. J Appl Pharma Sci 2013;3:35-42.

30. Sankula K, Kota S, Rao N. Formulation and evaluation of nizatidine mucoadhesive microspheres by ionic-gelation method. Eur J Pharm Sci Res 2014;1:3-9.

31. Pal R, Bhadoria AP, Ramteke S. Preparation and characterization of sodium alginate-Cbp-934P based mucoadhesive microbeads. Scholars Res Lib Pharm Lett 2011;3:1-1.

32. Jelvehgari M, Valizadeh H, Motlagh RJ, Montazam H. Formulation and physicochemical characterization of buccoadhesive microspheres containing diclofenac sodium. Adv Pharm Bull 2014;4:295-1.

33. Iswariya VT, Soujanya GL, Santhosh R, Kumar AP, Lingaswamy J, Satyanarayana K. Design and development of in vitro characterization of floating microspheres of ranolazine. Eur J Pharm Med Res 2016;3:220-32.

34. Swetha R, Baru CR, Vidyadhara S, Prakash KV. Formulation and evaluation of celecoxib bioadhesive microspheres. Indo Am J Pharm Sci 2014;1:407-19.

35. Jahan S, Sadat SM, Islam MR, Azam AT, Chowdhury JA. Effect of various electrolytes on theophylline loaded sodium alginate beads prepared by ionic cross linking technique. Dhaka Univ J Pharm Sci 2012;11:181-9.

36. Mane S, Ponrathnam S, Chavan N. Effect of chemical cross-linking on properties of polymer microbeads: A review. Canadian Chem Trans 2015;3:473-85.

37. Gavini V, Ragini B, Kaumudi K. Mucoadhesive microspheres-a novel approach of drug targeting. World J Pharm Pharm Sci 2014:3:310-35.

38. Chickering DE, Mathiowitz E. Bioadhesive microspheres: I. a novel electrobalance-based method to study adhesive interactions between individual microspheres and intestinal mucosa. J Control Rel 1995;34:251-61.

39. Rajinikanth PS, Sankar C, Mishra B. Sodium alginate microspheres of metoprolol tartrate for intranasal systemic delivery: Development and evaluation. Drug Deliv 2003;10:21-8.

40. Maddiboyina B, Asthana A, Asthana GS, Singh S, Ramya M, Sunnapu O, et al. Formulation and characterization of polycarbophil coated mucoadhesive microspheres of repaglinide. J Pharm Sci Res 2015;7:972-7.

41. Mandal S, Kumar SS, Krishnamoorthy B, Basu SK. Development and evaluation of calcium alginate beads prepared by sequential and simultaneous methods. Braz J Pharm Sci 2010;46:785-93.

42. Kulkarni N, Wakte P, Naik J. Development of floating chitosan-xanthan beads for oral controlled release of glipizide. Int $\mathrm{J}$ Pharm Investig 2015;5:73-80 